\title{
LA INTEGRACIÓN POLÍTICA DE NEGROS, MULATOS, PARDOS Y ZAMBOS AL ORDEN HISPÁNICO: LOS SITIOS DE LIBRES EN EL NUEVO REINO DE GRANADA
}

Jorge Conde Calderón

Universidad del Atlántico

Colombia

Hugues Sánchez Mejía Universidad del Valle Colombia 
Panorama Económico, Vol. 27 - No. 4 (Octubre - Diciembre de 2019), pp. 764-782

Jorge Conde Calderón

Hugues Sánchez Mejía

\title{
La integración política de negros, mulatos, pardos y zambos al orden hispánico: los sitios de libres en el Nuevo Reino de Granada
}

\section{Resumen}

Este trabajo analiza el ordenamiento político administrativo del territorio en los lugares donde habían surgido sitios de libres de todos los colores. También revisa el papel desempeñado por la vecindad para su integración al orden hispánico. Finalmente, presenta varios casos en que algunos libres, haciendo uso de condición de vecinos, aprovecharon los canales institucionales para acceder a empleos que estaban investidos de autoridad. Fue un proceso lleno de conflictos personales y vecinales que involucraron, en la mayoría de casos, a toda la comunidad.

Palabras clave: Integración política, Nuevo Reino de Granada, América

L'intégration de la politique des noirs, des mulâtres, des pardos et des zambos dans l'ordre hispanique: les sites des libérés au Nouveau Royaume de Grenade

\section{Résumé:}

Cet article analyse la manière dont s'est déroulé l'ordre politique administratif du territoire où des sites libres de toutes les couleurs avaient émergé. Egalement il passe en revue le rôle joué par le voisinage pour son intégration dans l'ordre hispanique. Finalement, il présente des cas des certains libres ayant utilisé des canaux administratifs pour accéder à des emplois ayant autorité en profitant du voisinage. Ce processus était accompagné de conflits personnels, avec le voisinage et dans certains cas avec la communauté.

Mots clés: Intégration politique, Nouvel Empire de Grenade, Amérique

Political integration of black, mulatto, brown, and mixed-race people to the hispanic order: the free sites in the New Kingdom of Granada

\begin{abstract}
This article analyzes the way in which the administrative political order of the territory took place where free sites of all colors had emerged. Also reviews the role played by the neighborhood for its integration into the Hispanic order. Finally, he presents cases of some free people who used administrative channels to access jobs with authority while taking advantage of the neighborhood. This process was accompanied by personal, neighborhood and, in some cases, community conflicts.
\end{abstract}

Keywords: Political integration, New Granada Empire, America 


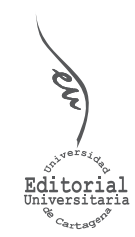

\section{La integración política de negros, mulatos, pardos y zambos al orden hispánico: los sitios de libres en el Nuevo Reino de Granada}

INFORMACIÓN DEL ARTícULO

Recepción del artículo: 03/12/2018

Concepto de evaluación: 04/03/2019

Aceptación del artículo: 03/07/2019
Jorge Conde Calderón Universidad del Atlántico, Colombia

Hugues Sánchez Mejía Universidad del Valle, Colombia

\section{INTRODUCCIÓN}

A partir del tercer decenio del siglo XVIII, la Monarquía Hispánica inició un proceso de reinvenciones institucionales para mantener e integrar sus posesiones ultramarinas en un moderno Estado de matices ilustrados con su respectivo andamiaje burocrático y la consecuente participación del denominado estado llano o común en dicha estructura política (Sánchez y Conde, 2019). Esas innovaciones políticas, económicas y administrativas conocidas como reformas borbónicas alcanzaron su mayor intensidad entre 1762 y 1787 durante el reinado de Carlos III. Aunque con un ritmo moderado también se hicieron reformas institucionales y fiscales tanto en anteriores como en posteriores reinados al de este monarca. Por lo tanto, resulta significativo el uso del reformismo borbónico como un concepto que reúne esas modificaciones, cambios y acciones en un solo agregado conceptual (Sánchez, 2007).

Entre esas innovaciones el reordenamiento del territorio ocupó la atención de los oficiales reales, lo cual consistía no solo en delimitar de "un modo ordenado y clasificado el material bruto de la extensión", sino también valorar "cada uno de los órdenes creados, jerarquizándolos" (Hespanha, 1993, p. 86).

En el proceso concurrieron prácticas jurisdiccionales y de gobierno que involucraban distintos agentes: virreyes, gobernadores, jueces, recaudadores de la real hacienda, clérigos o religiosos, vecinos y milicianos. Por lo general, todos actuaban sobre territorios ocupados por poblaciones emergentes dotándolos de elementos jurisdiccionales que confluían en el gobierno de un determinado territorio. Sin embargo, esos agentes, portadores de instituciones de gobierno, intervenían en espacios donde existían relaciones sociales complejas. Este hecho generó configuraciones espaciales en las cuales 
los vecinos tomaron iniciativas de orden local y maneras de organizar la vida política de los territorios que ocupaban. $\mathrm{Y}$ aunque sus acciones chocaban con las prácticas estructurantes de los funcionarios reales, la situación generada permitía a los vecinos el uso de los canales formales de comunicación política para lograr una interlocución casi directa con el virrey, el gobernador o los jueces de la Real Audiencia (Barriera, 2017; Barriera y Moriconi 2015; Barriera 2013; Damasceno, 2003; Barral y Fradkin, 2005).

En el Nuevo Reino de Granada, el virrey Sebastián de Eslava (1740-1749) inauguró ese proceso de cambios institucionales y reordenamiento político estableciendo la jurisdicción territorial de comunidades trasladas o asentadas en ciudades, villas, sitios y partidos. Pero su atención se centró en los denominados sitios de libres habitados por negros, zambos, mulatos y pardos. Estos grupos, considerados como los de mayor complejidad, en medio de un proceso sinuoso fueron asimilados al orden hispánico, logrando su concentración en poblaciones con trazados urbanísticos, reconociéndoles la condición de vecinos con privilegios y deberes, otorgándoles un terreno para sus labranzas y nombrándoles autoridades, jueces y recaudadores de las reales rentas. La mayoría de esos sitios fueron asimilados, en términos eclesiásticos, a la categoría de parroquias. Posteriormente, algunas de esas poblaciones transitaron un intrincado camino lleno de representaciones, suplicaciones y petitorios ante el rey para acceder a la categoría de villas.

En consecuencia, este artículo recrea esos elementos a partir de varios casos del problemático reordenamiento político del territorio en los llamados sitios de libres de todos los colores, teniendo en cuenta que ese proceso generó niveles de jerarquización entre esas poblaciones emergentes. Asimismo, revisa el papel desempeñado por la vecindad en su integración al orden hispánico. Finalmente, examina diferentes casos de algunos libres quienes haciendo uso de la condición de vecinos aprovecharon los canales institucionales para acceder a empleos como alcaldes pedáneos, cabos de justicia, tenientes de capitán a guerra y hasta capitanes a guerra. Esto originó situaciones signadas por conflictos personales y vecinales que perturbaban el orden cotidiano de las comunidades.

En términos generales, este artículo se aparta totalmente de una historiografía que consideró los sitios de libres como lugares ocupados por arrochelados que vivían sin Dios ni ley y, en el caso de los palenques, como símbolos de la libertad. Ese análisis del pasado fue acuñado a partir de interpretaciones sobre lo que expresaban los actores del período y corresponde a una orientación que es indispensable conocer, pero que no puede considerarse dominante o determinante para comprender y describir las sociedades del pasado (Herrera, 2010).

Las premisas de esa caracterización fueron establecidas a partir de lo señalado por uno de los actores: el arzobispo virrey Antonio Caballero y Góngora, quien en 1789 realizó para su sucesor en el cargo una evaluación del estado del virreinato. Como buen ilustrado católico describía lo que él consideraba un breve retrato de su irregular población con un modo de vida fuera del orden de policía. Esa población de hombres montaraces vivía, según el virrey, en sitios y lugares elegidos a su arbitrio, sin intervención del Gobierno monárquico ni tampoco de los jueces subalternos. Concluía su retrato señalando que esa numerosa población era "en realidad un monstruo indomable que a todo lo bueno se resiste” (Colmenares, 1989, p. 411). 
Según el virrey arzobispo, a esa sociedad heteróclita era necesario "sacarla de su infelicidad" a través de la aplicación de una sana política y bajo una recta administración de justicia para que aceptara con docilidad las providencias más benéficas del gobierno de su majestad. Similares caracterizaciones hicieron el obispo José Fernández Díaz de Lamadrid (Martínez, 1986) y el cura Joseph Palacios de la Vega (1994) con lo cual se ha difundido la idea de que la conservadora ilustración hispanoamericana tuvo como único propósito disciplinar a la plebe. Esto hizo perder de vista que una apreciable mayoría de funcionarios reales de talante liberal dedicaron buena parte de su tiempo a otorgar a los gobiernos de las Indias el estatus de reinos (Cañizares, 2005; Justiniano, 2017).

Uno de esos funcionarios fue un crítico mordaz del papel público escrito en 1789 por el virrey arzobispo. En 1803, el virrey Pedro Mendinueta lo consideró una pintura horrorosa de un monstruo inexistente. Eran solo exageraciones hijas de un celo desmedido, que cegaba la vista y confundía la pequeña parte con el todo, pero perjudiciales, porque presentaban una idea equivocada al Gobierno, cuyo ánimo podía "desfallecer con la representación de un desorden invencible, por lo general arraigado y de imposible remedio". Su conclusión era que, luego de quince años del citado papel, no podía "mudar de aspecto este país, y menos este Reino", Por el contrario: habían crecido los productos de la Real hacienda y los de las rentas decimales, los cuales eran un termómetro de la agricultura y la ganadería. Además, en la mayor parte de aquellos lugares, sus ciudades y villas estaban florecientes así como las parroquias, los pueblos españoles y cualquier caserío regular (Colmenares, 1989).

\section{DINÁMICAS DE LOS SITIOS DE LIBRES}

Muchos pueblos, sitios y lugares adquirieron vida institucional en la segunda mitad del siglo XVIII aunque su conformación fue producto de un lento proceso que se remontaba a centurias anteriores. En unas provincias como la de Santafé, que ocupaba una parte de lo que hoy denominamos altiplano cundiboyacense, los pueblos de indios se transformaron en parroquias de vecinos (Bonnet, 2001). En otras provincias como las de Cartagena, Santa Marta, Antioquia, Popayán y Mariquita los sitios de libres, una vez integrados al orden hispánico, tuvieron un reconocimiento simultáneo de parroquias, las cuales fueron concebidas mucho más que unidades administrativas eclesiásticas para la administración de los sacramentos a sus feligreses. Estos lugares tuvieron su trazado urbano que concentraba un vecindario campesino, y uno que otro comerciante y artesano. El mismo vecindario sostenía con sus actividades productivas y recursos económicos la parroquia a la cual se le asignaba un cura o párroco, aunque ellos también podían escogerlo resultando, por lo general, aquel emparentado con sus feligreses. Esta práctica contribuyó a institucionalizar un sistema de organización y control social del campesinado a través de las cofradías puestas bajo la advocación de un santo y vigiladas de cerca por aquellos (Martínez, 2018).

Esas características imprimieron un sello particular a esas comunidades campesinas ya que por su condición de parroquias carecieron de cuerpos intermedios como los cabildos de las ciudades y villas. Otra peculiaridad fue que en ellas se institucionalizaron minúsculos grupos de notables locales que ejercían la autoridad pública local en condición de alcaldes pedáneos o partidarios, los cuales eran escogidos, en algunas provincias por los gobernadores y en otras por los cabildos de las villas con jurisdicción sobre el sitio 
o parroquia. También merece destacarse que el desempeño de las magistraturas estaba motivado, fundamentalmente, por un valor que formaba parte de la tradición republicana clásica, según la cual la naturaleza humana florecía a través de la participación en la cosa pública. Esa tradición constaba de un conjunto de ideales y costumbres que se remontaban al pasado griego. No solamente promovían la participación en la vida pública a través de instituciones democráticas directas, sino también la autonomía (Guarisco, 2004).

Por consiguiente, en la administración de la parroquia o sitio se aplicaba un sistema de autogobierno en el cual la Junta de vecinos concentraba el poder decisorio cuando sus privilegios y costumbres estaban en riesgo por actos de gobierno contrarios a sus intereses. Se trataba de los llamados excesos en los que incurrían algunos funcionarios reales, o la intromisión de un hacendado o poderoso de la comarca, quienes transgredían competencias propias de la comunidad. Esto, que era permitido a la comunidad terminó como una práctica amparada en un marco jurídico político al abrigo de los privilegios, fueros y gracias reales. El resultado fue la equiparación de la junta vecinal abierta como una entidad corporativa dotada de su propia jurisdicción que mantenía incólume el poder político local y la denominada justicia pedánea (Rubio, 2017).

Ahora bien, los sitios de libres surgieron de diversas formas durante los siglos XVI y XVII. En algunos casos por asentamiento lento y espontáneo de negros, zambos, mulatos, pardos en los linderos de una hacienda o en las proximidades de reales de minas. Otras, por su aposentamiento en cruces de caminos o en los márgenes de los ríos, donde al final prosperaba un puerto fluvial a través del cual comerciaban mercaderías de manera legal o ilegal. En otros casos, vivían en territorios cercanos a ciudades y villas fundadas en los siglos señalados.

Como resultado del mestizaje y la diversidad étnica, su estatus jurídico era indefinido y estaban exentos de cargas y tributos por lo cual eran considerados libres. En el censo general de 1778 ordenado mediante real cédula para todo el territorio neogranadino los empadronadores los agruparon, demostrando cierta dosis de pragmatismo, en libres de todos los colores y alcanzaron un $46 \%$ del total de la población mientras que blancos, indios y esclavos sumaban 26\%, 20\% y $8 \%$ respectivamente (Conde, 1999; Mcfarlane, 1997). En censos particulares de un sitio o parroquia la performance burocrática del empadronador registraba con mayor detalle la calidad de los individuos elaborando un cuadro del mestizaje que mostraba una multiplicación de matices étnicos: zambos, pardos, mestizos, mulatos, blancos, cholos, cuarterones, indios, negros libres, esclavos negros, zambos o pardos (Solano, 2013).

Al momento de practicarse el censo general los libres estaban integrados políticamente luego de un proceso que comenzó en 1740 y que concluiría, transcurridos tres decenios, con la concentración de un campesinado libre, "que se llamaban vulgarmente montunos" en nuevas comunidades nucleadas, conocidas como sitios, lugares, curatos, parroquias, viceparroquias y villas (Conde, 1999). Esos campesinos, montunos, rústicos o labradores, para citar diferentes expresiones coetáneas del período, convivían como vecinos y lejos de la forma de vida arrochelada o de ocupar las rochelas, surgidas y que seguían existiendo en montes y breñas al margen de la jurisdicción del derecho castellano (Sánchez, 2015).

Por lo tanto, cuando el clérigo Josep Palacios de la Vega recorrió diez años después del censo, 1787-1788, el territorio fronterizo de las provincias de Cartagena y Antioquia donde los términos jurisdiccionales de cada una eran difusos, los sitios de libres estaban reordenados políticamente. Lo que describió en su Diario era la principal prueba de 
que el rostro humano del Estado ilustrado se había asomado en algunos territorios del virreinato (Monod, 1996).

Empero, en el clérigo franciscano todavía germinaba la idea de que el Estado se concentraba en el príncipe. Esto le generaba la creencia de que cédulas reales, decretos, reglamentos y otras normas expedidas por el rey tenían que aplicarse al pie de la letra por los oficiales reales del Estado y que su principal obligación era la destrucción de rochelas y congregar esa gente en civilidad como le escribiría al virrey José de Ezpeleta (Palacios, 1994, p. 12). Sin embargo, en el Diario de Palacios de la Vega está presente una etnografía del Estado, el cual, según el historiador Cañizares-Esguerra (2014), para funcionar y sobrevivir relativamente estable, por más de tres siglos siempre se construyó desde abajo.

En efecto, Palacios de la Vega muestra lo que ocurría en los estratos bajos de esas sociedades: la manera como los libres se apropiaban de formas estatales que combinaban con la costumbre, un valor inveterado en su ámbito cultural. Es decir, las prácticas reiteradas a lo largo del tiempo, hábitos consolidados que determinaban las disposiciones o inclinaciones de los individuos "para actuar o realizar determinadas acciones o para padecer determinadas pasiones y, lo que es más importante, que incluyen sus maneras de apreciarlas y evaluarlas" (Castro, 1999, p. 20).

El Diario caracteriza un mundo rural predominante donde los sitios de libres como núcleos urbanos articulaban una economía campesina con los grandes centros urbanos, principalmente la ciudad y plaza militar de Cartagena de Indias. Al emplear la palabra originaria campaña como "el campo igual, que no tiene montes, ni peñascos, y generalmente todo el sitio, que no tiene casas" (DRAE, 2017), describe la existencia "a un lado de la roza o vega de tabaco mettido en el monte [que los libres] ttenian otro rancho grande, donde ttenian alambiques de barro pa. sacar aguardte...caldo de caña, ornos y un grande cañaveral con ttoda la caña madura". También a "zambos ayapelanos" vendedores de su tabaco y aguardiente que producían en "la misma Villa [de Ayapel]" y en la jurisdicción de Majagual (Palacios, 1994, p. 54). El clérigo consideraba esa práctica "contrabando" que por vía fluvial pasaba por los puertos de Mompós y Magangué hasta llegar a Cartagena.

Reconocía que eran tierras aptas para la agricultura y la ganadería que contaban con la presencia de capitanes a guerra, Tenientes de "milicias de todos colores" y "como de aver spre. un tente. Capittan Agrra., un recaudador de Alcabalas y esttanco Real, de aver esttado spre. pronttos a el pago de las Alcabalas, como obedtes. a los mandatos de ttodas aquellas Justticias" (Palacios, 1994, p. 65). Es importante resaltar esto último porque demuestra todo lo contrario de una situación que él intentaba corregir. Un territorio con gobierno económico y político, pero incomprendido por un Palacios de la Vega intransigente que terminó "solo en la campaña" enfrentado y acusado ante sus superiores por el poder de los notables locales y vecinos de cometer tropelías y "excesos" (Palacios, 1994, 71).

Por consiguiente, Palacios de la Vega no lograba comprender que, en ese tipo de sociedades, los vínculos de individuo a individuo desempeñaban un papel determinante en las prácticas políticas. Eran sociedades en las cuales la vida social dependía del compromiso tácito contraído por sus miembros y en la cual todo acuerdo era resultado de negociaciones, en las cuales cualquiera de las partes estaba lejos de imponer su voluntad (Laslett (1967). Similares planteamientos han sido señalados por la historiadora Mariana Canedo sobre la formación de "pueblos de españoles" en Buenos Aires. Aunque 
las diferencias étnicas, culturales o económicas entre esos pueblos y los sitios de libres son notables, en ambos casos el proceso tenía en común la existencia de tensiones, dilaciones y conflictos generados a partir de la aplicación de jurisdicciones tendientes al autogobierno, lo cual estuvo inscrito en la urdimbre de relaciones de poder, negociaciones y coyunturas de cambio (Canedo, 2016).

En el caso de los sitios de libres, las sociedades construidas manejaban unas jerarquías simplificadas más horizontales que verticales sobre la base de redes sociales tejidas entre las justicias de los sitios, los mayordomos de los hatos que abastecían de carnes los sitios y villas alejadas del poder político de la ciudad principal, los roseros de maíz, los estancieros de plátanos y cacao, los "ganaderos" (llamados así quienes trabajaban como vaqueros o peones en los hatos), los tabacaleros, los destiladores de aguardiente, los propietarios de los astilleros establecidos en la margen de los ríos y los negociantes que les vendían "ropa al fiado a aquellas genttes" que en la noche se reunían con "un grande ruido de tambores y grittera. de baile" adquiriendo la característica de sociedades de una clase (Palacios, 1994; Laslet, 1967).

De igual manera, cuando Palacios de la Vega recorrió la provincia de Cartagena ya habían transcurrido entre diez y treinta años de ejecutadas las políticas repobladoras en las provincias de Cartagena y Santa Marta de José Fernando de Mier y Guerra, Francisco Pérez de Vargas y Antonio de la Torre y Miranda, entre otros, quienes encontraron cuadros similares al descrito por Palacios de la Vega. Sin embargo, a diferencia de éste último, negociaron con los denominados arrochelados su asentamiento en núcleos urbanos, permitiéndoles cultivar sus parcelas, destilar aguardiente, participar en el juego de los intercambios económicos directos. En algunos casos, les permitían trabajar en haciendas, estancias y tierras de las notabilidades del lugar, como las del maestre de campo Mier y Guerra, el Conde de Pestagua, el Marqués de Valdehoyos y otros sin títulos nobiliarios, pero con el título de don o doña. Muchas de esas propiedades habían sido adquiridas del remate de tierras que antes estuvieron vacantes o destinadas a la utilidad general como tierras del común.

Esos elementos confluyeron en la problemática fundación de Santa Cruz de Pizarro, en 1751, cuando Francisco Pérez de Vargas y el Justicia Mayor del Partido de Tierradentro, Andrés de Madariaga, se asociaron para que les asignaran "ocho caballerías de tierras, con calidad de poblarlas en sociedad de veinticuatro vecinos", en la jurisdicción de la Provincia de Santa Marta. El hecho fue denunciado por Mier y Guerra porque solo ellos las disfrutaban en compañía de dos o tres vecinos "sin formalidad de asignación, pues tienen sus casas y familia en el sitio de la Soledad", jurisdicción de la provincia de Cartagena (Archivo General de la Nación (AGN), Poblaciones, t. 10, f. 918).

La denuncia del maestre de campo no obedecía a las preocupaciones de un celoso funcionario por evitar apropiaciones de tierras realengas o comunales con el pretexto de poblarlas o entregarlas a vecinos libres pobres. Era la respuesta de un hacendado y militar que veía invadido su espacio de poder por unos competidores con iguales privilegios a los suyos. 


\section{EL GOBIERNO ECONÓMICO Y POLÍTICO DEL TERRITORIO}

Uno de los principales elementos abordados por los reformistas borbónicos fue estructurar un gobierno económico y político acorde con las circunstancias demográficas y económicas de ciudades, villas, sitios y partidos del Nuevo Reino de Granada. El proceso comenzó por algunas ciudades y villas que mostraban cuadros fiscales deplorables y en los sitios de libres que, en contraste con aquellas, daban señales de un dinamismo poblacional y económico pero que su población vivía en un relativo nivel de autonomía adquirido por la escasa atención del Estado y la problemática condición jurídica de sus pobladores.

El proceso de consolidación política del territorio donde estaban localizados los sitios de libres oscilaba entre la coerción y la aplicación de medidas liberales. Por ejemplo, la repoblación de la provincia de Santa Marta realizada por el hacendado, maestre de campo y vecino de la villa de Mompós, José Fernando de Mier generó enfrentamientos entre los vecinos y los hacendados de la comarca. A eso se le sumó que el traslado forzoso de gente a la mayoría de los 22 sitios arreglados política e institucionalmente presentó un carácter conflictivo (Mier, 1987). El otro ejemplo, fue la acción repobladora realizada por Antonio de la Torre y Miranda, un militar ilustrado quien estuvo bajo las órdenes de Manuel Guirior quien, luego en su condición de virrey del Nuevo Reino, le ordenó a su compañero de armas la reubicación a son de campana de 44 sitios de libres localizados en las Sabanas de Tolú y Corozal (Conde, 1999).

Esos dos casos y las posteriores visitas del oidor Juan Antonio Mon y Velarde a varios pueblos de la provincia de Antioquia (1788-1790), la del visitador general de las provincias de Santa Marta y Río del Hacha y de Santa Cruz de Mompós, Manuel Antonio Rubianes (1790) y la visita pastoral del obispo de Cartagena Diego de Peredo (1772), proporcionan suficientes elementos para concluir que los sitios de libres había sido integrados "de la mejor manera" al orden hispánico (AGN, Visitas Antioquia, t. 2, f. 1067; Visitas Magdalena, t. 1, f. 891; Peredo, 1972).

La fórmula sobre el mejor gobierno económico y político extendido a la mayoría de los sitios de libres, incluía dos componentes: El primero, el reordenamiento del territorio reinventando partidos con "alguna jurisdicción o administración de una Ciudad principal" o en ocasiones una villa denominada "cabeza" (DRAE, 2017). También fueron definidos los distritos rurales que, bajo la jurisdicción eclesiástica dependían de un cura quien administraba la parroquia como parte territorial de la diócesis correspondiente al obispado ya fuese en Cartagena, Popayán, Santa Marta, Antioquia o en cada una del resto de provincias del Nuevo Reino.

Los informes de los visitadores reales permiten seguir el curso del establecimiento de ese novedoso reordenamiento político en el territorio del Nuevo Reino de Granada. Sus escritos contienen sutiles acercamientos económicos, etnográficos y culturales de los nuevos territorios que ellos consideraron imprescindibles instrumentos para su gobernabilidad ya fuera política o religiosa. También se advierte en sus informes el alto grado de compromiso de la figura del visitador con la empresa que llevaba a cabo: la del funcionario solidario con los propósitos del Estado. Eran pretensiones e intenciones estatales que habían cambiado de manera sustancial en el siglo XVIII con el reformismo borbónico (García, 2017). 
En el Nuevo Reino la mayoría de provincias procuraron la atención de los visitadores ilustrados. En la gobernación de Popayán el informe de Josef Antonio Pando, en 1770, ofrece un panorama de la forma como estaban organizados los asentamientos de las jurisdicciones de las diferentes ciudades y villas provinciales. Con relación a los sitios de libres que se habían creado este funcionario les garantizó el mantenimiento de sus posesiones y aprobó títulos a los vecinos estableciendo linderos de sus tierras, siendo San Antonio de Quilichao el caso más palpable (Herrera, 2009; Bolaños, 2016). Luego, la Relación, en 1797, de Diego Antonio Nieto (1983), señalaba con mayor detalle el nombre y número de sitios y pueblos integrados en cada uno de los dieciséis partidos que componían la provincia y gobernación de Popayán.

Luego de su visita pastoral a la provincia de Cartagena, el obispo Diego de Peredo elaboró un informe detallado de los once partidos que la componían y de cada una de las ciudades, villas, pueblos de indios, sitios, parroquias, feligresías, viceparroquias y curatos que los integraban. El clérigo fue muy cauteloso al presentar las autoridades civiles de cada partido y lugar, pero reiterativo en el empleo de la expresión parroquia de libres al momento de detallar lo que los empadronadores denominaron sitios de libres (Peredo, 1972).

El reconocimiento de un sitio como parroquia y feligresía incluía tanto elementos de la vida municipal como de los de jurisdicción eclesiástica. Sin embargo, en algunos sitios antes de ser erigidos en parroquias hubo presencia de eclesiásticos que administraban los asuntos espirituales del lugar. En ocasiones llegaron a liderar entre los vecinos los petitorios de erección en parroquia.

El sitio de libres de Barranquilla en la jurisdicción del partido de Tierradentro de la provincia de Cartagena, que había surgido y crecido, en términos demográficos y económicos, en las márgenes de la hacienda "San Nicolás" era administrado en temas eclesiásticos por Luis Suárez, cura del pueblo de indios de Ciénaga en la provincia de Santa Marta. Este clérigo se trasladaba religiosamente al sitio para oficiar la Santa Eucaristía y atender sus negocios particulares de prestamista y en calidad de recaudador de los réditos generados por las capellanías. En 1734 aparece establecido en Barranquilla y, con el apoyo económico de los vecinos más pudientes, inició la construcción de la iglesia que permitió trece años después la erección en parroquia del sitio (Blanco, 2011).

La presencia de los curas en los sitios de libres fue determinante para arreglar su gobierno político y económico. Los curas y vecinos actuaban muy ligados generando tensiones y conflictos con las nuevas autoridades, jueces y justicias que empezaban a ejercer cargos en los sitios, parroquias o villas. En Chiriguaná, jurisdicción de la provincia de Santa Marta, ante la ausencia de jueces laicos, la administración de la justicia estaba a cargo del cura de la parroquia y feligresía. Solo hasta mediados del siglo XVIII el gobernador nombró a los primeros jueces (Conde, 2013).

Esos casos peculiares generaban quejas de los jueces inferiores y religiosos del bajo clero ya que la situación originada parecía irremediable. El 30 de octubre de 1784 "el humilde capellán" Ignacio Xavier Arias de Bustamante y el alcalde pedáneo Jacinto Andrés de la Barrera y Ferro informaron al gobernador de Cartagena sobre la situación intolerable surgida en la parroquia de Nuestro Señor de los Milagros de Pueblo Viejo ya que "Aquí todos son juezes, todos mandan, hasta las mujeres (hablo señor Excmo) con la debida venia, y por esta causa, no hay término" AGN, Miscelánea, t. 11, f. 671). 
En otras ocasiones, los términos de la ecuación cambiaban de manera radical cuando una población pasaba un largo tiempo sin eclesiástico que les administrara los santos sacramentos como aconteció en 1802 con los vecinos de Barichara. Estos aprovecharon la demora que presentaba el nombramiento del cura para solicitar hacer uso del privilegio de elegirlo. Tanto en el tribunal de la Real Audiencia de Santafé como en la Curia Metropolitana radicaron representaciones cuyo argumento principal era que, en 1752, los fundadores del pueblo no hicieron uso de ese privilegio cuando el sitio fue erigido en parroquia. Ahora, después de transcurridos cincuenta años, ellos estaban convencidos de que ese privilegio no se había extinguido por cuanto: "Los beneficios del Príncipe son siempre permanentes. La ley estaba escrita, y el servicio que [...] hicieron a la iglesia y al Estado no ha perdido su mérito ni su recompensa" (AGN, Curas y obispos, t. 49, f. 366). Antes de radicar su petitorio ante las superiores justicias, secular y eclesiástica, se reunieron como "el Cuerpo de vecinos principales que componen este lugar" para notificarle al alcalde partidario Manuel José de Vargas sobre el poder concedido a Luis de Ovalle y Cándido Nicolás Girón. En su concepto estos procuradores de número debían actuar en representación del vecindario para hacer realidad "sus propios derechos y decisiones".

Esas representaciones, quejas, reclamos o petitorios en los sitios de los libres eran elaborados por legos en materia jurídica, quienes a veces se hacían pasar por abogados pero eran la nota predominante en los lugares de sociabilidad adonde concurrían sin excepción las justicias de los sitios, igualmente legos, los religiosos subalternos del cura, y los vecinos: pulperías, tiendas y las entradas de las iglesias, antes o luego de la misa. Allí se disertaba en voz alta sobre temas variados que iban desde el buen gobierno pasando por los comentarios sobre la vida cotidiana del pueblo, los populares chismes, hasta juicios sobre las actuaciones públicas y privadas de los funcionarios. Muchas veces esos espacios se escuchaban rumores que propiciaban las denuncias ante el superior gobierno.

La denuncia ocupaba un lugar central en el sistema social y político. No en vano los jueces eran llamados oidores y los inspectores fiscales veedores. El énfasis en los ojos y los oídos como órganos rectores del cuerpo político revelaba la naturaleza del Estado moderno hispánico que debía disponer de sus más leales súbditos en el gobierno de las nuevas poblaciones (Cañizares, 2014, p. 182).

El acto de denunciar no siempre era exitoso para quien lo realizaba y hasta podía terminar pasando a ocupar el lugar del acusado. Esto le ocurrió a Pedro López natural de los Reinos de España, vecino del sitio de Corozal y residente en la ciudad de Cartagena. En 1807, este denunciaba a quien había sido Alcalde de la Santa Hermandad de la jurisdicción de Corozal, don José Guerrero Cavero y otros de su parcialidad "comprendidos en el comercio de tabaco que contra los bandos públicos se introducían por ellos en los lugares de aquel distrito con perjuicio de la Real Hacienda". El superior gobierno encargó al alcalde ordinario de primera nominación de la villa de San Benito de Abad para que con base en el conocimiento de la causa "la sustancie y determine con dictamen de asesor letrado oyendo los recursos en lo que haya lugar" (AGN, Juicios Criminales, t. 188, f. 316). La primera conclusión del alcalde fue que López también era contrabandista, lo cual generó que la causa se prolongara superando los términos señalados por la ley e involucrando otras autoridades y jueces, los cuales eran considerados personas honorables de acreditada conducta, distinguidos servicios para con el Rey y la Patria y declarados buenos ciudadanos. 
Por consiguiente, el nombramiento de funcionarios, constituye el segundo componente de nuestro análisis. Un empleo importante por su jerarquía y poder político fue el de Capitán a guerra, funcionario nombrado directamente por el virrey. Los Capitanes a guerra administraban justicia y gobierno en la jurisdicción de los partidos. Un partido estaba compuesto de sitios de libres, pero también de pueblos de indios. Por tanto, el título del Capitán a guerra llevaba anexo el de Corregidor de naturales. Igual ocurría cuando había reales de minas: el título incluía el de alcalde mayor de minas. Una reforma de 1783 les había suprimido a los Capitanes a guerra funciones militares. A cambio de ello se convertían en jueces territoriales independientes cuyo empleo incluía funciones de justicia mayor, corregidor de naturales, juez ordinario y de comisos, recaudador de tributos y de rentas reales, alcalde mayor de minas y teniente oficial real (Conde, 2016).

Los Capitanes a Guerra escogían sus oficiales. Uno principal, el Teniente de Capitán a guerra, quien lo reemplazaba durante las ausencias temporales o cuando aquel salía en comisión o visitaba otros sitios de libres o pueblos de indios de su jurisdicción para recaudar impuestos o tributos. Siempre iban acompañados de dos cabos de justicia que se ocupaban de velar por el cumplimiento por parte de los vecinos de las labores de policía, ornato y aseo de la plaza y las calles.

El poder acumulado y concentrado por los Capitanes a guerra era objeto de fuertes disputas con otras autoridades sobre temas de competencias y jurisdicciones. El Estado estuvo atento a corregir abusos, extralimitación de funciones y excesos contra los vecinos, pero aconsejaba a quienes practicaban causas sumarias contra los Capitanes a guerra actuar con prudencia y tacto. El Visitador General Manuel Antonio Rubianes dio señales de seguir esos consejos cuando con éxito plausible realizó el "mejor arreglo de los capitanes a guerra y los jueces" en la conflictiva provincia de Santa Marta (AGN, Residencias Magdalena-Bolívar-Tolima-Venezuela, t. 64, f. 48).

Como la mayoría de jueces del mundo rural un número considerable de los Capitanes a guerra eran legos, aunque buena parte importante de ellos adquirió un relativo nivel de instrucción a través de la lectura indirecta de "Verdaderos Prontuarios de Perfección" como el manual del Corregidor perfecto o el de Lorenzo Santayana, El corregidor, y alcalde, o juez del pueblo complemento indispensable de su Govierno político de los pueblos de España (Álvarez, 2012; Guardiola, 1796; Santayana, 1742).

Pero esos funcionarios enriquecían su conocimiento con elementos jurídico-políticos propios de la tradición republicana clásica. Ello no solamente constituía una continuidad en el universo cultural de Occidente, sino que tenía sustento ideológico en las Siete Partidas, el derecho canónico y romano y las ordenanzas municipales. Estas últimas eran una especie de constitución local que regía la vida ciudadana desde los aspectos políticos de gobierno hasta las normas de policía e higiene pública (Rubio, 1981; Pérez, 1931, Guarisco, 2014).

El reconocimiento político de esos sitios también generó una multiplicación de alcaldes pedáneos. Estos impartían justicia ordinaria y eran seleccionados de una terna por el gobernador de la respectiva provincia, aunque en su momento el virrey Eslava hizo uso de esa potestad (AGN, Empleados Públicos de Bolívar, t. 30, f. 553). En algunos casos el nombramiento también la practicaban los cabildos de las villas cuando estas ejercían jurisdicción partidaria sobre los sitios o parroquias. En su condición de jueces de primera instancia, los alcaldes pedáneos fueron reemplazando a los alcaldes de la hermandad. De igual manera, administraban justicia respaldados por dos cabos de justicia, a quienes 
aquellos les delegaban competencias que no correspondían a su empleo con lo cual terminó imponiéndose la costumbre de algunos alcaldes pedáneos de no residir en los sitios de su jurisdicción y las poblaciones terminaban entonces "gobernados por los cabos de justicia que por lo general son zambos o negros” (AGN; Empleados Públicos de Bolívar, t. 10, f. 393).

Todos esos agentes sociales representaban el gobierno de la justicia y jugaron un papel importante como articuladores entre las poblaciones urbanas y las rurales. Su presencia fue preponderante en los puertos fluviales, barrancas, apostaderos y pequeños astilleros localizados en las proximidades de los ríos Magdalena, Cauca, San Jorge, Lebrija y Pamplona. También en los territorios de las provincias de Cartagena, Antioquia, Girón, Santa Marta, Popayán, Panamá y Chocó.

\section{VECINDAD Y TERRITORIALIDAD}

El proceso de integración política de los sitios de libres no estuvo exento de la coerción física. Por consiguiente, se consideró necesario proteger jurisdiccionalmente las nuevas poblaciones contra las arbitrariedades y abusos cometidos por gobernadores, alcaldes ordinarios, regidores, cabildos, capitanes a guerra, alcaldes pedáneos, hasta cabos de justicia y los personajes poderosos de la comarca (Garriga, 2002).

En 1795, los libres de Chiriguaná reclamaron unas tierras adyacentes. Se dio inicio entonces a una querella judicial en la que ellos incluían la aspiración a ser erigidos en villa. Para tal efecto aducían tener una iglesia ornamentada, cofradía, pagar diezmos, obedecer a su Capitán a guerra y alcalde pedáneo, producir lo necesario para abastecer ciudades y comarcas cercanas, poseer derechos sobre tierras comunales y el uso sobre los playones formados luego de concluida la temporada de lluvias. Aunque los intereses de poderosos y notables de la comarca se oponían a la aspiración de esos pobladores, en 1804 el gobierno de Santafé determinó adjudicar al sitio tres estancias de tierras en compensación a los servicios prestados a la Corona y por vivir siempre bajo "arreglo político", en vecindad (Sánchez, 2011).

Por consiguiente, integrar a los libres también significó reinventar la vecindad. El término vecino se originó en Castilla en los siglos XI y XII, durante la época de la reconquista y repoblación. Fue solicitada de manera voluntaria por quienes deseaban abandonar sus comunidades de origen y establecerse en tierras recuperadas a los musulmanes. Tenía su fundamento en el ius comune aunque la comunidad estaba convencida de que era una ley natural. Como acto voluntario siguió funcionando hasta el siglo XVI y así fue trasladada a tierras americanas. Pero en los siglos XVII y XVIII, al perder su relación con la inmigración esa característica se modificó y adquirió el carácter de implícita (Herzog, 2006).

Ese carácter de la vecindad en los territorios de la Monarquía Hispánica señalaba una diferencia sustancial con Francia e Inglaterra, en los cuales la comunidad del Reino se identificaba progresivamente con el monarca y el Estado Centralizado. En el modelo policéntrico de la Monarquía Hispánica, los mecanismos de naturalización y avecindamiento se fundamentaban en el consenso de la comunidad local y no en la mera decisión del monarca o el virrey. Esto aseguraba la autonomía de las distintas corporaciones, ciudades, villas, parroquias, en las cuales el vecino era el jefe de familia que podía ser miembro de los gremios y miembro practicante de las cofradías (Herrero, 
2017, p. 31). Por lo tanto, la vecindad estaba definida por los vínculos que las personas generaban con una comunidad, ya fuese por el simple hecho de formar parte del grupo que fundaba u organizaba la comunidad o porque según la costumbre estaban allí cuando se reordenó la población por acción de algún agente ilustrado.

En 1798 los campesinos del sitio de libres de Chinú, en la provincia de Cartagena, en medio de una querella judicial contra autoridades foráneas que intentaban desconocer la costumbre de que los vecinos solo participaban en la construcción de caminos reales, recordaban que veinticuatro años atrás Antonio de la Torre por orden del gobierno virreinal los reunió en calidad de vecindario libre, trazó plaza y calles, erigió iglesia, entregó terrenos para cultivar y nombró autoridades civiles y eclesiásticas (AGN, Juicios Criminales, t. 187, f. 367).

La integración política a la comunidad era fundamental ya que las personas tenían conocidos con quienes podían contar, participaban en festividades, procesión del santo patrono, actos litúrgicos durante la Semana Santa y compartían ritos y costumbres locales. La pertenencia definida a una comunidad permitía disponer de las pruebas necesarias para poner fin a un conflicto, contar con testigos para impedir o permitir un matrimonio entre iguales, los cuales entre los libres mostraban ya jerarquías del color y la producción de etiquetas étnicas (Faberman, 2016).

En 1790 José Paternina, un pardo del sitio de Sincelejo, en la provincia de Cartagena, promovió una querella judicial contra José Manuel Bertel para impedir el matrimonio de este con su hija Candelaria. El argumento principal de Paternina era que su hija era blanca y Bertel hijo de un mulato y una cuarterona. Lo complejo del pleito colocaba en aprietos al alcalde ordinario de la villa de San Benito Abad y su jurisdicción ya que debía dictar sentencia. Pero al igual que el alcalde de Antioquia en 1794, tenía que consultar al superior gobierno sobre si era "justo el disenso de los mestizos, chavones o quarterones para no casarse con mulatos" (AGN, Genealogías, t. 6, f. 399). Aunque Paternina y Bertel eran pardos, lo cual los hacía iguales, el primero estaba por encima del segundo ya que ocupaba un nivel superior en la jerarquía social y política: era un oficial real del gobierno hispánico en el sitio.

Los conflictos por la posición según la jerarquía de los colores incidían en el nombramiento de una persona de color en un empleo. En 1795 el cura de la ciudad de Cáceres, en la provincia de Antioquia, denunciaba al Capitán a guerra Manuel de Lara por haber nombrado como sus Tenientes a Blas y Murciano Cárcamo, hijos de una mulata de Mompós, y también al zambo de indio Martín Gómez como Cabo de justicia. El gobernador justificaba los nombramientos de los dos mulatos y el zambo indio afirmando que, aunque esa era "una vecindad noble y no todos son mulatos negros zambos libertinos, todos del pie mondado, y las malas inclinaciones" los mulatos Cárcamos y el zambo indio Gómez como forasteros eran imparciales y seguirían "la voz del rey y no la parcialidad de aquella plebe que habitan en la ciudad” (AGN, Miscelánea, t. 343, f. 321).

La acción del Capitán a guerra erosionaba un sistema social en el que la identidad política debía coincidir con la identidad social, la cual no era individual sino corporativa y dotada de privilegios particulares específicos. La vecindad era a la vez concreta y territorial y como tal escapaba, a una perfecta generalización. Pero su ejercicio permitía cierto nivel de participación política que, acorde con una sociedad ligada a una estructura clasificatoria y de una concepción jerárquica, buscaba la consolidación de grupos caracterizados por niveles de riqueza y de poder, con privilegios especiales. Todo ello les 
garantizaba el control jurídico de los municipios mediante el manejo de mecanismos de inclusión/exclusión que contraponían en sus extremos las condiciones del vecino y del forastero. La vecindad permitía también al nivel microcósmico del sitio o la parroquia, la reproducción de los principios y criterios que caracterizaban la naturaleza del súbdito a nivel macropolítico del reino, como opuesto al extranjero (Carziolo, 2002).

Así, las acciones de los agentes del Estado ilustrado ratificaban la importancia de la integración política de los sitios de libres y su reconocimiento. Ello propiciaba una mutación de las calidades, las cuales ahora comenzarían a estar determinadas por el poder de la riqueza. La concesión de privilegios y la exigencia de cumplir deberes por los vecinos de los sitios de libres se concedían a cambio de que, entre sus deberes, ellos aceptaran el pago de cargas impositivas.

El gobernador de Popayán, Juan Antonio Nieto era muy claro cuando afirmaba que los sitios y pueblos eran capaces de "rendir muchos más si se procura y fomenta la útil ocupación de las muchas manos ociosas que quedan en él". Esto también lo señalaban los vecinos de sitios de libres como Tuluá y Llanogrande (actual Palmira) cuando cursaban petitorios para ser elevados a la categoría de villas. Sin embargo, a quien recordaban y citaban era al visitador Pando quien les había insistido en la riqueza material de sus lugares (Nieto, 1983).

De esas transformaciones políticas no escapaban aquellos lugares, que los historiadores consideran espacios supremos de la libertad, como el sitio y feligresía del Palenque de San Basilio. Entre 1791 y 1792 se libraría un pleito entre el Capitán del pueblo de "vecinos negros" Melchor de los Reyes, el cura José Cayetano Lozano y el gobernador de Cartagena Joaquín de Cañaveral. Lo que interesa de este expediente es que revela la organización del pueblo dirigido por un Capitán con funciones civiles y jurisdicción solo en los términos de la parroquia, unos subalternos con funciones específicas y unos vecinos negros obligados a entregar en sus fechas las primicias eclesiásticas, pagar derechos de alcabala y los diezmos de lo cual se encargaban el cura del pueblo y los recaudadores de las reales rentas (AGN, Juicios Criminales, t. 267, f. 263).

Lo relevante de los casos citados es que estos agentes sociales llegaban a los pueblos con un discurso ilustrado y liberal propio de la época sobre la forma más útil para arreglarse en el mejor orden para el beneficio de la Republica, entendida en su sentido originario de Respública que "es un cierto orden o manera de vivir instituida y escogida entre sí por quienes viven en la misma ciudad". Ello quería decir: "por ninguna otra cosa es averiguado quien sea el ciudadano, sino por la participación del poder para juzgar y determinar públicamente" (Castrillo, 1958).

\section{Reflexiones finales:}

\section{EL USO DE LAS EXPRESIONES SITIOS, PUEBLOS/PUEBLO}

El discurso liberal ilustrado tuvo su impacto y fue apropiado con relativa facilidad por la gente de esos pueblos, en su mayoría negros libres, zambos, mulatos y pardos. Esto se debía a la inexistencia de cuerpos intermedios como los cabildos u oligarquías urbanas poderosas que influyeran de manera decisiva o impusieran sus intereses particulares. 
La introducción de expresiones como República, Estado, Soberanía, Pueblo, Ciudadano y otras del registro político en sus acepciones hispánicas comenzaba a ser frecuente entre ellos. Por ejemplo, los vecinos del sitio de Chinú en su querella judicial contra las medidas injustas del regidor provincial y capitán a guerra del partido de San Benito de Abad argumentaban que esos individuos carecieron de "Maestro para adquirir alguna educación civil, y que los objetos que se le presentaron, además de que fueron los más adecuados para continuar en corromperle, no eran capaces de labrar [...], un miembro útil, ni de infundirle aquella ciencia que hace conocer mejor los deberes, que la razón natural dicta, para que la criatura se acerque al creador, el hijo se estreche con el padre, el súbdito obedezca al superior, y los ciudadanos se unan entre sí, con vínculos indisolubles de religión, y razón" (AGN, Juicios Criminales, t. 187, f. 482).

Por su lado, los "sujetos acomodados" de la villa de Ayapel para rechazar a un Capitán a guerra por no pertenecer a su comunidad sino que era un "forastero" vociferaban ser "los que públicamente prestan la voz de un Pueblo" y consideraban para ese empleo a uno de ellos por ser "un hombre republicano" (AGN, Visitas Bolívar, t. 7, f. 906). Cabe anotar, que en esos pueblos esa noción dominante tenía su fundamento en la más importante manifestación del republicanismo político de Castilla, como se considera en el Tratado de Castrillo: Republicano es un hombre de representación capaz de oficios públicos (Castrillo, 1958).

De igual manera, las acciones emprendidas por los agentes reformistas posicionaron a los sitios de libres, llamados en ocasiones pueblos o el pueblo, como cuerpos políticos de la monarquía hispánica. La acepción pueblo remitía al "lugar o ciudad que está poblado de gente" (DRAE, 2017). La generalización de la expresión pueblo fue más frecuente a finales del siglo XVIII y su empleo remitía a una corporación con personalidad jurídica. En otras palabras, una corporación política de personas con un gobierno y derechos que reunida en junta legitimaba por aclamación las iniciativas de dos, tres o más vecinos.

Con la independencia política, en 1810, la denominación sitios de libres de todos los colores dejó de emplearse y se generalizó la expresión pueblo o pueblos, los cuales iniciarían un doble proceso de igualación social. El primero, la gradual desaparición del régimen de los privilegios personales con la respectiva igualación de los varones adultos como ciudadanos; el segundo, la lenta disolución del régimen de preeminencias, fueros y privilegios de las poblaciones que comenzaron a ser igualadas todas ellas con el sustantivo municipio. Algunas de esas poblaciones obtuvieron de las nuevas autoridades el título de villa, distinción por la cual habían elevado, sin éxito alguno, innumerables petitorios ante los funcionarios de la corona. En la nueva situación, generada por los acontecimientos revolucionarios, ese título lo obtenían por su participación en la defensa de los valores republicanos implícitos en las constituciones políticas de los estados provinciales.

\section{REFERENCIAS BIBLIOGRÁFICAS}

Archivo General de la Nación (AGN), Colombia, Bogotá.

Álvarez, M. (2012). Corregidores y alcaldes mayores. La administración territorial andaluza en el siglo XVIII. España: Universidad de Alicante.

Barral, M. y Fradkin, R. (2005). Los pueblos y la construcción de las estructuras de poder institucional en la campaña bonaerense (1785-1836). Boletín del Instituto de Historia Argentina y Americana "Dr. Emilio Ravignani", 27, 7-48. 
Barriera, D. (2013) Abrir las puertas a la tierra. Microanálisis de la construcción de un espacio político. Santa Fe, 1573-1640. Santa Fe: Ministerio de Innovación y Cultura de la Provincia de Santa Fe.

Barriera, D. (2017). La política desde el campo: iniciativas locales y gobierno rural en tiempos reformistas (Santa Fe, virreinato del Río de la Plata a finales del siglo XVIII). Revista de Indias, 77(270), 521-549.

Barriera, D. y Moriconi, M. (2015). Gobiernos y territorialidades: Coronda, de caserío a curato (Santa Fe, Gobernación y Obispado de Buenos Aires, 1660-1749). DOI: 10.4000/nuevomundo.67858.

Blanco, J. (2011) Obras completas. Barranquilla: Universidad del Norte.

Bolaños, R. (2016). Accediendo a la tenencia de la tierra: integración política de los libres de San Antonio de Quilichao en la jurisdicción de aloto, provincia de Popayán (1740-1808). Recuperado de http://ojs.udc.edu.co/index.php/taller/article/ view/694.

Bonil, K. (2011). Gobierno y calidad en el orden colonial. Las categorías de mestizaje en la provincia de Mariquita en la segunda mitad del siglo XVIII. Bogotá: Universidad de los Andes.

Bonnet, D. (2001). De la conformación de los pueblos de indios al surgimiento de las parroquias de vecinos. El caso del altiplano cundiboyacense. DOI: https://doi. org/10.7440/res10.2001.01

Canedo, M. (2016). Los 'pueblos de españoles' en la monarquía hispánica. La ampliación de jurisdicciones hacia el autogobierno (Buenos Aires, siglo XVIII y primeros años del XIX). Prohistoria 19(25), 3-27.

Cañizares, J. (2014). La memoria y el estado: la monarquía de España en el siglo XVI. Iberoamericana, 14(54), 177-185.

Cañizares, J. (2005). La Ilustración hispanoamericana: una caracterización. En J. Rodríguez (Ed.), Revolución, independencia y las nuevas naciones de América. (pp. 87-98). Madrid (España): Fundación Mapfre Tavera.

Castro, Luis (1999). Sed buenos ciudadanos. Caracas, Ediciones Alfadil.

Carziolo, M. (2002). En los orígenes de la ciudadanía en Castilla. La identidad política del vecino durante los siglos XVI y XVII. Hispania, 62 (42), 637-691.

Castrillo, A. (1958). Tractado de la República (1521). Madrid: Instituto de Estudios Políticos.

Colmenares, G. (1989) Relaciones e informes de los gobernantes de la Nueva Granada. Bogotá: Fondo de Promoción de la Cultura del Banco Popular.

Conde, J. (1999). Espacio, sociedad y conflictos en la Provincia de Cartagena, 1740-1815. Barranquilla: Universidad del Atlántico.

Conde, J. (2013). La administración de justicia en las sociedades rurales del Nuevo Reino de Granada, 1739-1803. Historia Crítica, 49, 35-54.

Conde, J. (2016). Capitanes a Guerra: Gobierno económico y político en el Virreinato del Nuevo Reino de Granada. Historia Caribe, 11 (29), 155-182. 
Damasceno, C. (2003). Funções, hierarquias e privilégios urbanos. A concessão dos títulos de vila e cidade na Capitania de Minas Gerais. Varia Historia 29, 29-51.

Dubet, A. (2007). ¿La importación de un modelo francés? Acerca de algunas reformas de la administración española a principios del siglo XVIII. Revista de Historia Moderna, 25, 207-233.

Faberman, J. (2016). Imaginarios sociales en la colonia tardía, Clasificaciones y jerarquías del coloro en los llanos de la Rioja, siglo XVIII y XIX. En F. Guzmán, L. Geler y A. Frigerio (Eds.). Cartografías afrolatinoamericanas. Perspectivas situadas desde la Argentina (pp. 25-49). Buenos Aires (Argentina): Editorial Biblos.

García, F. El libro de viajes, la figura del visitador y la reescritura literaria del acto jurídico n El Lazarillo de ciegos caminantes. Recuperado de http://www.lehman.edu/ faculty/ guinazu/ ciberletras/v14/haberly.htm.

Garriga, C. (2002). Los límites del reformismo borbónico: a propósito de la administración de la justicia en Indias. En F. Barrios (Ed.), Derecho y administración pública en las Indias hispánicas: Actas del XII Congreso Internacional de Historia de Derecho Indiano (pp. 781-821). Madrid (España): Universidad de Castilla-La Mancha, Ediciones Institucionales.

Guardiola, L. (1796). El corregidor perfecto. Madrid: Imprenta Real.

Guarisco, C. (2004). ¿Reyes o Indios? Cabildos, repúblicas y autonomía en el Perú y México coloniales, 1770-1812. Revista Andina, 39, 203-226.

Herrera, M. (2009). Popayán: La unidad de lo diverso. Territorio, población y poblamiento en la provincia de Popayán, siglo XVIII. Bogotá: Ediciones Uniandes.

Herrera, M. (2010). "El arrochelamiento: nominar para criminalizar". Recuperado de https://doi.org/10.32997/2382-4794-vol.2-num.2-2010-653.

Herrero, M. (2017). Repúblicas y republicanismo en la Europa moderna (siglo XVI-XVIII). Madrid: FCE-Red Columnaria.

Herzog, T. (2006). Vecinos y extranjeros. Hacerse español en la edad moderna. Madrid; Alianza editorial.

Hespanha, A. (1993) La Gracia del derecho. Economía de la cultura en la edad moderna. Madrid: Centro de Estudios Constitucionales.

Justiniano, M. (2016). América: de colonia a reino y de periferia a centro. Recuperado de http://journals.openedition.org/nuevomundo/69742

Laslett, P. (1967). "The face to face society". En P. Laslett (Ed.), Philosophy, Politics and Society (pp. 157-184). Oxford: Basil Blackwell.

Martínez, A. (2018), Poblamiento, jurisdicción y estatus en la experiencia urbana neogranadina. Texto cedido por el autor

Mcfarlane, A. (1997). Colombia antes de la independencia. Economía, sociedad y política bajo el dominio Borbón. Bogotá: Banco de la República/El Áncora Editores.

Martínez, G. (1986). Cartas de los obispos de Cartagena de Indias durante el período hispánico, 1534-1820. Medellín: Editorial Zuluaga.

Mier, J. (1987). Poblamiento de la Provincia de Santa Marta. Siglo XVIII. Bogotá: Colección de las Academias de Colombia y Libreros colombianos. 
Monod, P. (1996). Estado, nación y monarquía en el siglo XVIII: visión comparativa. En C. Russel y J. Gallego (Eds.). Las Monarquías del Antiguo Régimen, ¿monarquías compuestas? (pp. 11-29). Madrid (España): Editorial Complutense.

Nieto, D. (1983). Visita de la gobernación de Popayán (1797). Cespedesia, 12(45-46), 495-511.

Palacios, J. (1994). Diario de viaje, entre los indios y negros en la Provincia de Cartagena en el Nuevo Reino de Granada. 1787-1788. Barranquilla: Ediciones de la Gobernación del Atlántico.

Peredo, D. (1972). Noticia historial de la Provincia de Cartagena de Indias año 1772". Anuario Colombiano de Historia Social y de la Cultura, 2(6-7), 119-154.

Pérez, J. (1931). Instituciones de Derecho Histórico Español (Derecho público). Barcelona: Librería Bosch.

Rubio, L. La justicia pedánea, el concejo y la gestión del común como referentes en el funcionamiento de las comunidades rurales del Reino de León durante la edad moderna. http://www4.fe.uc.pt/aphes31/papers/sessao_6e/laureano_rubio_ paper.pdf.

Rubio, L. (1981), Ordenanzas municipales como fuente para el análisis socioeeconómico de la ciudad de León durante el antiguos régimen. Tierras de León. Revista de la Diputación Provincial, 45, 38-63.

Sánchez E. (2016). Las reformas borbónicas como categoría de análisis en la historiografía institucional, económica y fiscal sobre Nueva España: orígenes, implantación y expansión. Historia Caribe, 11(29), 19-51.

Sánchez, H. (2015). De arrochelados a vecinos: reformismo borbónico e integración política en las gobernaciones de Santa Marta y Cartagena, Nuevo Reino de Granada, 1740-1810. Revista de Indias, 75(264), 457-488.

Sánchez, H, (2011). De esclavos a campesinos, de la "roza" al mercado: tierra y producción agropecuaria de los "libres de todos los colores" en la gobernación de Santa Marta (1740-1810)". Historia Crítica, 43, 130-155.

Sánchez, H. y Conde, J. (2019). Entre la asignación de privilegios, el Estado y la causa pública: tierras y oratorio para el asiento de libres de Quilichao, Popayán, 17501810. Anuario Colombiano de Historia Social y de la Cultura, $N^{\circ} 46(1), 59-83$.

Santayana, L. (1742). El corregidor, y alcalde, o juez del pueblo. Zaragoza: Imprenta de Francisco Moreno.

Solano, S. (2013). Padrones de población e historiografía sobre la configuración socio-racial hispanoamericana del siglo XVIII. Recuperado de http://dx.doi. org/10.32997/2382-4794-vol.5-num.5-2013-708. 